\title{
Determination of available and carbonate antimony (Sb) in soil by Atomic Fluorescence Spectrometry
}

\author{
Xiaoyan $\mathrm{Ge}^{1,2}$, Qian $\mathrm{Mo}^{3}$, Guofeng Wang ${ }^{4, *}$, Yan Zhao ${ }^{1, *}$, Yongyu $\mathrm{Li}^{1}$, Shihua Wang ${ }^{1}$ \\ ${ }^{1}$ Shanghai Urban Construction Vocational College, Shanghai, 200438, China \\ ${ }^{2}$ College of Environmental Science and Engineering, State Environmental Protection Engineering Center for Pollution Treatment and \\ Control in Textile Industry, Donghua University, 201620, Shanghai, China \\ ${ }^{3}$ Shanghai ZhiXian Project Management Consulting Co., LTD, Shanghai, 201499, China \\ ${ }^{4}$ Luoyang Ecological Environment Monitoring Center of Henan province, Luoyang 471002, China
}

\begin{abstract}
Antimony (Sb) is a toxic and potentially carcinogenic metalloid element. The toxicity of Sb in the environment strongly relies on its speciation. It is necessary to investigate the speciation and content of antimony in soil in order to understand better the real risk associated with $\mathrm{Sb}$ in the environment. This study developed water bath heating and soaking-AFS methods to determine the available and carbonate antimony in soil. Through analysis and mutual verification experiments in three different laboratories, the repeatability and reproducibility in the precision experiment were less than 3.44 , the average recovery rate was more than $98.1 \%$. These methods were accurate, reproducible and effective for detecting the content of available and carbonate antimony in soil.
\end{abstract}

\section{Introduction}

Antimony (Sb) is a kind of metalloid widely existing in nature, which has the characteristics of high toxicity and long-distance migration[1]. As the world's leading antimony producer, China has accounted for approximately $80 \%$ of the world's annual $\mathrm{Sb}$ production over the last decade [2-3]. In the process of antimony mining and processing, antimony- containing waste will be produced, which not only causes environmental pollution, but also produces serious toxicity to organisms[4,5]. Antimony can be taken up by plants and photosynthetic biofilms and thereby enter the food chains resulting in environmental pollution [6]. Previous studies have shown that the content of antimony in mature leaves up to $150 \mathrm{mg} / \mathrm{kg}$ will produce toxic effect on plants[7]. The toxic effects are as follows: reducing the activity of cell enzymes, affecting the production of reactive oxygen species, inhibiting chlorophyll synthesis, destroying cell metabolism and the dynamic balance of growth system, and producing oxidative stress effect [8].

$\mathrm{HB}$ Li et al. found that antimony can bind to sulfhydryl $(-\mathrm{SH})$ in human proteins, and has strong some thiol enzymes such as succinate oxidase, interfere with the metabolism of protein and sugar in the body, thus inducing liver cirrhosis, nephritis, pancreatitis and other diseases, and even cancer in severe cases [9].

Currently, the commonly used determination method of antimony are atomic fluorescence spectrometry (AFS) [10], atomic absorption spectrometry (AAS)[11], inductively coupled plasma mass spectrometry (ICP-
MS)[12], inductively coupled plasma atomic emission spectrometry (ICP-OES)[13], and so on. Among them, atomic fluorescence spectrometer has high popularity, wide application range, low price and low operation cost. The prior results showed that the linear range of determination of antimony in cosmetics by AFS was good, and the correlation coefficient R2 was 0.9984 [14]. Comparing the two methods of AFS and ICP-MS in analyzing antimony concentration in water, both methods had a low detection limit. Meanwhile, both methods showed good linearity, precision and accuracy[15]. At the same time, L Zhao et al. also established a microwave digestion-AFS method for the determination of antimony in grubs, and the results were accurate and reproducible [16-20]. However, there are few reports on the determination methods of antimony in soil, especially the pretreatment method. Therefore, it is necessary to investigate the content of exchangeable antimony in soil, not only for the human health, but also for the sustainable development of ecological environment.

The objectives of this study were to 1) develop a new method of determining the content of available and carbonate antimony in soil, water bath heating and soaking-atomic fluorescence spectrometry (AFS) methods; 2) conduct experimental verification in three laboratories with different instruments; 3) assess the precision (repeatability and reproducibility) and accuracy of different pretreatment methods.

\footnotetext{
* Corresponding author: lywgf19790501@163.com

yanyangzhao@163.com
} 


\section{2 instrument and reagent}

\subsection{Instrument}

Atomic fluorescence spectrometer (AFS-830、AFS-9230、 AFS-8130)、Electric thermostatic water bath (DZKW-SA-4), One in ten thousand analytical balance (BT125D).

\subsection{Reagent}

Antimony standard solution $100 \mu \mathrm{g} \cdot \mathrm{mL} \quad-1 \quad$ (China Academy of metrology, batch No: GBW(E)080545); Hydrochloric acid and sodium hydroxide were superior grade purity. Potassium borohydride, thiourea and diethylenetriamine pentaacetic acid (DTPA) were analytically pure. The water is ultra-pure water (the soil samples, standard samples and reagents of the three laboratories are the same).

\section{Method and result}

\subsection{Sample pretreatment}

\subsubsection{Extraction of available antimony}

$25.0 \mathrm{~g}$ soil sample (accurate to $0.0001 \mathrm{~g}, 20 \mathrm{mesh}$ ) were weighed and put into a $150 \mathrm{~mL}$ conical flask, and the extract of $50.0 \mathrm{~mL}$ DTPA were added. After shaking for 2 $\mathrm{h}$, the solution was filtered and transferred into a $50 \mathrm{~mL}$ colorimetric tube. Appropriate amount of ultrapure water, $2.5 \mathrm{ml}$ nitric acid and $5.0 \mathrm{ml}$ thiourea solution were added. The solution was diluted to the mark with ultra-pure deionize water, shaken evenly and stood $30 \mathrm{~min}$ for determining. Meanwhile, procedural blanks were run during the procedure.

\subsubsection{Extraction of carbonate antimony}

$30.0 \mathrm{~g}$ soil sample (accurate to $0.01 \mathrm{~g}, 20 \mathrm{mesh}$ ) were weighed and put into $240 \mathrm{~mL}$ sodium acetate solution (1 $\mathrm{mol} / \mathrm{L}$ ). After shaking for $2 \mathrm{~h}$, the exchangeable supernatant was discarded and $240 \mathrm{ml}$ sodium acetate solution were added to the residue. After shaking for $8 \mathrm{~h}$, the solution was filtered and transferred into a $50 \mathrm{~mL}$ colorimetric tube for determination. Meanwhile, procedural blanks were run during the procedure.

\subsection{Drawing of standard curve}

$0 \mathrm{ml}, 0.50 \mathrm{ml}, 1.00 \mathrm{ml}, 2.00 \mathrm{ml}, 4.00 \mathrm{ml}, 8.00 \mathrm{ml}$ and 10.0 $\mathrm{ml}$ antimony standard solution were transferred into seven $50.0 \mathrm{ml}$ volumetric flasks, respectively. $2.5 \mathrm{ml}$ hydrochloric acid and $5.0 \mathrm{ml}$ thiourea solution were added. The solution was diluted to the mark with ultra-pure deionize water, shaken evenly and stood $30 \mathrm{~min}$ for determining. The concentrations of each volumetric flask were $0 \mu \mathrm{g} \cdot \mathrm{L}-1 、 1.00 \mu \mathrm{g} \cdot \mathrm{L}-1 、 2.00 \mu \mathrm{g} \cdot \mathrm{L}-1 、 4.00 \mu \mathrm{g} \cdot \mathrm{L}$ $-1 、 8.00 \mu \mathrm{g} \cdot \mathrm{L}-1 、 16.0 \mu \mathrm{g} \cdot \mathrm{L}-1 、 20.0 \mu \mathrm{g} \cdot \mathrm{L}-1$, respectively.

\subsection{Determination}

The instruments were adjusted to the best working conditions according to the operation manual. The operating parameters of the AFS are shown in Table 1. Hydrochloric acid solution was used as the carrier current, and the fluorescence values of the solutions were measured. The detection limit of the method was $0.20 \mu \mathrm{g} \cdot \mathrm{L}$ -1 . The detection limit was $0.10 \mathrm{mg} \cdot \mathrm{kg}-1$ when the sample weight was $0.1 \mathrm{~g}$ (accurate to $0.0001 \mathrm{~g}$ ) and the constant volume was $50.0 \mathrm{ml}$.

Table1. Instrument parameters for AFS

\begin{tabular}{ll}
\hline Parameters & Operating setting \\
\hline Lamp current & $60 \mathrm{~mA}$ \\
Negative pressure & $270 \mathrm{~V}$ \\
Carrier gas flow & $400 \mathrm{~mL} \cdot \mathrm{min}-1$ \\
Shielding gas flow & $1000 \mathrm{~mL} \cdot \mathrm{min}-1$ \\
Atomizer temperature & $200^{\circ} \mathrm{C}$ \\
\hline
\end{tabular}

\subsection{Result calculation}

Available and carbonate antimony in soil samples:

$$
W_{1}=\frac{\left(C_{1} \times 50.0 / V-C_{0}\right) \times R}{(1-f) \times 1000}
$$

Where W1 $(\mathrm{mg} \cdot \mathrm{kg}-1)$ is the content of antimony in soil. $\mathrm{C} 1 \quad(\mu \mathrm{g} \cdot \mathrm{L})$ is the concentration of antimony from calibration curve, $\mu \mathrm{g} \cdot \mathrm{L}-1 . \mathrm{V}(\mathrm{mL})$ is the volume of the extracted liquid.CO $(\mu \mathrm{g} \cdot \mathrm{L}-1)$ is the concentration of blank sample. $\mathrm{R}$ is the ratio of water/soil $[\mathrm{V} / \mathrm{W}(\mathrm{ml}: \mathrm{g})=2$ for available antimony, $\mathrm{V} / \mathrm{W}(\mathrm{ml}: \mathrm{g})=8$ for carbonate antimony]. $f(\%)$ is the moisture content of soil sample.

\subsection{Precision test of available antimony}

According to the above determination method, three actual samples from each laboratory were analyzed, and the parallel determination was conducted for six times. For available antimony, the standard deviation between laboratories was $0.031 \sim 0.482$, and the relative standard deviation was between $1.6 \% \sim 3.1 \%$; the repeatability of this method was between $0.11 \sim 3.33$, and the reproducibility was between $0.42 \sim 3.37$ (Table 2). 
Table2. Precision test data of available antimony in three laboratories

\begin{tabular}{|c|c|c|c|c|c|c|c|c|c|}
\hline \multirow{2}{*}{ NO. } & \multicolumn{3}{|c|}{ Sample I } & \multicolumn{3}{|c|}{ Sample II } & \multicolumn{3}{|c|}{ Sample III } \\
\hline & $\bar{X}_{1}$ & $\mathrm{Si}$ & RSD & $\bar{X}_{1}$ & $\mathrm{Si}$ & RSD & $\bar{X}_{1}$ & $\mathrm{Si}$ & RSD \\
\hline 1 & 2.00 & 0.1080 & 5.4 & 12.32 & 0.3307 & 2.7 & 25.70 & 0.6207 & 2.4 \\
\hline 2 & 1.96 & 0.1191 & 6.1 & 12.49 & 0.8402 & 6.7 & 25.37 & 1.4948 & 5.9 \\
\hline 3 & 1.94 & 0.1139 & 5.9 & 11.77 & 0.5172 & 4.4 & 24.75 & 1.2788 & 5.2 \\
\hline $\bar{X}$ & 1.97 & & & 12.2 & & & 25.3 & & \\
\hline $\mathrm{S}$ & 0.031 & & & 0.376 & & & 0.482 & & \\
\hline RSD & 1.6 & & & 3.1 & & & 1.9 & & \\
\hline $\mathrm{r}$ & 0.11 & & & 1.68 & & & 3.33 & & \\
\hline $\mathrm{R}$ & 0.42 & & & 1.70 & & & 3.37 & & \\
\hline
\end{tabular}

NO.: Lab number; $\overline{\bar{X}_{1}}:$ Mean concentration;

Si: Standard deviation;

RSD: Relative standard deviation;

r: Repeatability; R: Reproducibility

\subsection{Precision test of carbonate antimony}

For carbonate antimony, the standard deviation between laboratories was $0.067 \sim 0.295$, and the relative standard deviation was between $1.5 \% \sim 1.9 \%$; the repeatability of

this method was between 0.60 3.27, and the reproducibility was between 1.72 3.44 (Table 3).

Table3. Precision test data of carbonate antimony in three laboratories

\begin{tabular}{|c|c|c|c|c|c|c|c|c|c|}
\hline \multirow{2}{*}{ NO. } & \multicolumn{3}{|c|}{ Sample I } & \multicolumn{3}{|c|}{ Sample II } & \multicolumn{3}{|c|}{ Sample III } \\
\hline & $\bar{X}_{1}$ & $\mathrm{Si}$ & RSD & $\bar{X}_{1}$ & $\mathrm{Si}$ & RSD & $\bar{X}_{1}$ & $\mathrm{Si}$ & RSD \\
\hline 1 & 4.22 & 0.1296 & 3.1 & 10.56 & 1.1420 & 10.8 & 19.51 & 1.4662 & 7.5 \\
\hline 2 & 4.13 & 0.2352 & 5.7 & 10.84 & 1.11427 & 10.5 & 18.99 & 1.0610 & 5.6 \\
\hline 3 & 4.26 & 0.2560 & 6.0 & 10.97 & 0.9863 & 9.0 & 19.01 & 0.9048 & 4.8 \\
\hline $\bar{X}$ & 4.20 & & & 10.79 & & & 19.17 & & \\
\hline S & 0.067 & & & 0.209 & & & 0.295 & & \\
\hline RSD & 1.6 & & & 1.9 & & & 1.5 & & \\
\hline $\mathrm{r}$ & 0.60 & & & 3.06 & & & 3.27 & & \\
\hline $\mathrm{R}$ & 1.72 & & & 3.0 & & & 3.44 & & \\
\hline
\end{tabular}

NO.: Lab number; $\overline{\mathrm{X}}_{1}$ : Mean concentration;

Si: Standard deviation; RSD: Relative standard deviation;

r: Repeatability; R: Reproducibility

\subsection{Standard addition recovery test}

Three soil samples were prepared by adding two concentrations of antimony standard solution $(2 \mu \mathrm{g} \cdot \mathrm{L}-1$, $10 \mu \mathrm{g} \cdot \mathrm{L}-1)$. The samples were determined six times in parallel in three laboratories. The recovery rates were as follows (Table 4). For available antimony, the average recovery rate were between $99.8 \% \sim 100.3 \%$, and the standard deviations were between $3.5 \sim 4.1$. And for carbonate antimony, the average recovery rate were between $98.1 \% \sim 99.4 \%$, and the standard deviations were between $0.85 \sim 1.11$.

Table4. Standard addition test data of available antimony in three laboratories

\begin{tabular}{|c|c|c|c|c|c|c|}
\hline \multirow{3}{*}{ NO. } & \multicolumn{2}{|c|}{ Sample A } & \multicolumn{2}{|c|}{ Sample B } & \multicolumn{2}{|c|}{ Sample C } \\
\hline & $\mathrm{P}_{\mathrm{i}}$ & & $\mathrm{P}_{\mathrm{i}}$ & & $\mathrm{P}_{\mathrm{i}}$ & \\
\hline & AA & $\mathrm{CA}$ & AA & $\mathrm{CA}$ & $\mathrm{AA}$ & $\mathrm{CA}$ \\
\hline 1 & 99.5 & 97.8 & 99.3 & 98.1 & 101.2 & 99.7 \\
\hline 2 & 103.5 & 98.6 & 104.9 & 97.2 & 102.6 & 100.1 \\
\hline 3 & 96.5 & 100.0 & 96.8 & 98.9 & 95.5 & 98.4 \\
\hline $\mathrm{P}$ & 99.8 & 98.8 & 100.3 & 98.1 & 99.8 & 99.4 \\
\hline $\mathrm{S}_{\mathrm{P}}$ & 3.5 & 1.11 & 4.1 & 0.85 & 3.8 & 0.89 \\
\hline
\end{tabular}

NO.: Lab number; Pi: Standard recovery;

P: Mean of standard recovery;

AA: Available antimony; CA: carbonate antimony. 


\section{Discussion}

In pretreatment of soil samples, microwave digestion, automatic digester digestion, soaking method and water bath heating method were conducted in three laboratories, respectively. Finally, only soaking and water bath heating method were found to work best, and the qualified rate of standard samples reached $93.3 \% ; 10 \%$ parallel sample analysis was carried out for actual samples, which were all within the maximum allowable deviation range. Therefore, soaking and water bath heating method are effective for digestion of soil samples.

Additionally, through the analysis of the same samples with different concentrations in three laboratories, the results showed that the standard deviation of available antimony precision test was $0.031 \sim 0.482$, the repeatability and reproducibility were less than 3.3 , indicating that the determination results had high accuracy and good reproducibility. Meanwhile, the average recovery rate for available antimony were between $99.8 \% \sim 100.3 \%$. In addition, the average recovery rate for carbonate antimony was between $98.1 \% \sim 99.4 \%$, indicating that the method is suitable for the analysis of soil available antimony. In summary, the method of water bath heating/soaking atomic fluorescence spectrometry for the determination of antimony content in soil has the advantages of simplicity, accuracy, high accuracy and low cost.

\section{Acknowledgments}

This study was supported by the Fundamental Research Funds for the Central Universities and Graduate Student Innovation Fund of Donghua University (Grant No.CUSF-DH-D-2020074), the scientific research project of Shanghai Urban Construction Vocational College (Grant No.cjky202111).

\section{Reference}

1. ZP Ning. Antimony pollution characteristics and source analysis of soil antimony pollution around a antimony smelter in high antimony geological background area [C]. Chinese society of mineral petrogeochemistry, 2019:933-934.

2. He M, Wang X, Wu F, Fu Z. Antimony pollution in China. Sci Total Environ[J]. 2012;421-422:41-50.

3. DC Guo., ZZ Fan., SY Lu et al.Changes in rhizosphere bacterial communities during remediation of heavy metal-accumulating plants around the Xikuangshan mine in southern China[J]. Sci Rep. 2019; 9: 1947.

4. AP Yuan., YL Huang., YX Tang. Determination of trace Selenium and bismuth in antimony concentrate by hydride generation-atomic fluorescence spectrometry $[\mathrm{J}]$. Physical and chemical inspection (Chemical Division), 2009,45(10):1184-1186.

5. YH.,BR Duan. Study on toxic effect of Antimony and its emission standard [J]. Journal of Hunan Institute of Humanities and technology, 2007(06):29-31.

6. DX Zhang. Effects of antimony stress on Seed Germination and seedling growth of crops [D]. Northwest Agriculture and Forestry University, 2015.

7. MC He., HY Wan. Distribution, presence, toxicity and bioavailability of antimony in the environment $[\mathrm{J}]$. Progress in chemical, 2004(01):131-135.

8. Xue L, Ren H, Li S, et al. Comparative proteomic analysis in Miscanthus sinensis, exposed to antimony stress [J]. Environmental Pollution, 2015, 201(14):150-160.

9. HB Li., ZH Yang., PF Yuan et al. Pollution characteristics of soil heavy metal Antimony in Antimony mining area of Central Hunan province [J]. Environmental science and technology, 2011,34(01):70-74.

10. SH Li., RX Chen., FY He et al. Determination of antimony in ambient water samples by atomic fluorescence spectrometry [J]. Modern instrument, 2011,17(03):79-80.

11. X Wu., Y Weng., YB Xiao et al. Determination of trace Antimony in environmental water samples by Ngraphite furnace atomic absorption spectro-metry enriched by nano titanium dioxide[J].Journal of Analytical Science,2004(04):376-378.

12. FM Ye., Xiang Zhang. Comparison of determination methods of arsenic, mercury, selenium and antimony in food by ICP-MS and AFS [J]. Grain, oil and food science and technology, 2016,24(01):77-80.

13. Y Wei., XL Dou., LP Ju et al. Determination of Antimony in Gold and antimony ores by Tetracytic acid-Inductively coupled Plasma Emission Spectrometry [J]. Rock ore testing, 2013,32(05):715718.

14. X Zhou., YH Wang., XJ Jiang et al. Determination of arsenic, antimony, lead and mercury in cosmetics by microwave digestion - atomic fluorescence spectrometry [J]. Daily chemical industry, 2019,49(11):764-768.

15. ZH Wang., T Xia., CF Hua et al. Comparison of determination of antimony in water by AFS and ICPMS [J]. Water purification technology, 2019, 38(11): 13-17.

16. L Zhao., BL Liu., HR Jiang et al. Determination of Selenium-mercury-antimony in grubs by microwave digestion-AFS [J/OL]. Modern Chinese Medicine:16[2020-01-12]. 1673-4890. 20190412003.

17. Water quality. Determination of arsenic. Atomic fluorescence method (SL327.1-2005)

18. Technical specifications for soil environmental monitoring (HJ/T166-2004)

19. Gravimetric method for determination of dry matter and moisture in soil (HJ 613-2011)

20. JM Serafimovska., S Arpadjan., T Stafilov. Study of the antimony species distribution in industrially contaminated soils[J]. J Soils Sediments (2013) 13:294-303. 